\title{
Leg Volume and Mass Scales of Elite Male and Female Athletes in Some Olympic Sports
}

\author{
Sevde Mavi $\operatorname{Var}^{1, *} \&$ Irfan Marangoz ${ }^{1}$ \\ ${ }^{1}$ University of Kirsehir Ahi Evran, School of Physical Education and Sports, Kirsehir, Turkey \\ *Correspondence: School of Physical Education and Sports, University of Kirsehir Ahi Evran, Kirsehir, Turkey. Tel: \\ 90-554-450-0016 E-mail: sevde.mavivar@ahievran.edu.tr
}

Received: June 14, 2018

Accepted: July 10, 2018 Online Published: August 3, 2018

doi:10.5430/wje.v8n4p54

URL: https://doi.org/10.5430/wje.v8n4p54

\begin{abstract}
This study aims to scale average leg volume and mass scales of elite male and female athletes in some olympic sports. A total of 280 elite athletes comprising of 200 males and 80 females studying at School of Physical Education and Sports at University of Kirsehir Ahi Evran voluntarily participated in this study. Frustum and Hanavan methods were used to determine leg volume and mass, respectively. SPSS 22.0 package program for Windows was used for descriptive statistics analysis of the study. The present study found average leg volume and mass scale of male athletes in football, basketball, volleyball, handball, gymnastics and wrestling and female athletes in football, basketball, volleyball, handball, gymnastics, box, taekwondo and tennis. It was observed in the related scale that leg volume of the athletes in the lowest weight classes in weight sports were lower. In other words, leg volume and mass of the athletes were in direct proportion to their weight class. When the scale of female athletes is analyzed, it can be noted that volleyball players have the highest leg volume and mass among team sports players.
\end{abstract}

Keywords: Leg volume, leg mass, scale

\section{Introduction}

An athlete needs a certain amount of muscle balance in order to use his/her strength and display a better performance (Baecchle, \& Earl, 2000). Muscle balance is related to a muscle or a group of muscles moving in a certain or reverse direction. Strength balance can be considered as a more accurate parameter for sports performance compared to absolute strength because an athlete's absolute strength is equal to his/her muscle or muscle groups with the lowest strength (Astrand et al., 2003).

It is reported in the literature that performance and strength values are positively influenced by leg volume, leg muscle volume and fat-free leg volume. Muscle balance is related to a muscle or a group of muscles moving in a certain or reverse direction (Shumway, \& Woollocatt, 2007). Athletes with a higher anaerobic performance are known to have higher muscle mass and cross-sectional area, leg volume and leg mass (Staron et al., 2000). Muscle fibril length, leg volume and muscle mass play an important role in the muscle strength in anaerobic sports (Armstrong et al., 2001; De Ste Croix et al., 2001). Muscle volume, mass and cross-sectional area on the leg affect muscle strength (Ozkan, \& Isler, 2010). In this respect, this study aims to contribute to the literature by creating a scale of right and left leg volume and mass of athletes in different olympic sports.

\section{Material and Methods}

A total of 200 male athletes comprising of 30 football players with $21.46 \pm 1.91$ years of age, $79.00 \pm 5.09 \mathrm{~kg}$ and $181.33 \pm 6.39 \mathrm{~cm}, 30$ basketball players with $22.56 \pm 2.10$ years of age, $80.10 \pm 5.09 \mathrm{~kg}$ and $180 \pm 3.50 \mathrm{~cm}, 30$ volleyball players with $22.46 \pm 1.91$ years of age, $81.00 \pm 5.09 \mathrm{~kg}$ and $183 \pm 5.39 \mathrm{~cm}, 30$ handball players with $23.60 \pm 2.26$ years of age, $78.10 \pm 5.09 \mathrm{~kg}$ and $179 \pm 5.40 \mathrm{~cm}, 30$ gymnasts with $21.60 \pm 1.28$ years of age, $75.33 \pm 5.25 \mathrm{~kg}$ and $176 \pm 4.40 \mathrm{~cm}$, 10 wrestlers (freestyle and Greco roman) with $23.20 \pm 2.10$ years of age, $65.30 \pm 5.15 \mathrm{~kg}$ and $176 \pm 4.40 \mathrm{~cm}, 10$ wrestlers (freestyle and greco roman) with $22.15 \pm 1.50$ years of age, $70.10 \pm 5.30 \mathrm{~kg}$ and $176 \pm 4.40 \mathrm{~cm}$, 10 wrestlers (freestyle and greco roman) with $22.22 \pm 1.20$ years of age, $74.25 \pm 4.15 \mathrm{~kg}$ and $176 \pm 4.40 \mathrm{~cm}, 10$ wrestlers (freestyle and greco roman) with $22.22 \pm 1.30$ years of age, $85.50 \pm 6.20 \mathrm{~kg}$ and $176 \pm 4.40 \mathrm{~cm}, 5$ wrestlers (freestyle and greco 
roman) with $21.52 \pm 2.10$ years of age, $97.46 \pm 3.15 \mathrm{~kg}$ and $176 \pm 4.40 \mathrm{~cm}$, and 5 wrestlers (freestyle and greco roman) with $23.62 \pm 1.30$ years of age, $125.40 \pm 4.15 \mathrm{~kg}$ and $176 \pm 4.40 \mathrm{~cm}$ voluntarily participated in the study. In addition, a total of 80 female athletes comprising of 10 female football players with $20.35 \pm 1.20$ years of age, $68.12 \pm 3.09 \mathrm{~kg}$ and $176.11 \pm 4.10 \mathrm{~cm}, 10$ female basketball players $20.56 \pm 1.20$ years of age, $75.20 \pm 2.09 \mathrm{~kg}$ and $179 \pm 3.40 \mathrm{~cm}, 10$ female volleyball players with $21.46 \pm 1.90$ years of age, $70.10 \pm 5.20 \mathrm{~kg}$ and $180 \pm 2.30 \mathrm{~cm}, 10$ female handball players with $22.60 \pm 2.20$ years of age, $75.20 \pm 4.01 \mathrm{~kg}$ and $175 \pm 4.37 \mathrm{~cm}, 10$ female gymnasts with $21.20 \pm 1.15$ years of age, $65.03 \pm 2.25 \mathrm{~kg}$ and $170 \pm 2.40 \mathrm{~cm}, 10$ female boxers with $22.40 \pm 1.15$ years of age, $70.33 \pm 5.25 \mathrm{~kg}$ and $172 \pm 3.40 \mathrm{~cm}$, 10 taekwondo players with $21.10 \pm 1.18$ years of age, $72.43 \pm 4.25 \mathrm{~kg}$ and $179 \pm 2.40 \mathrm{~cm}$, and 10 tennis players with $22.10 \pm 1.13$ years of age, $74.08 \pm 6.20 \mathrm{~kg}$ and $172 \pm 6.40 \mathrm{~cm}$ participated in the study, too. Frustum and Hanavan methods were used to determine leg volume and mass, respectively.

\subsection{Calculation of Leg Volume and Mass}

Femur, calf and feet were measured in order to calculate leg volume. The distance between tibial point and inguinal fold was calculated to find the femur volume. After this distance was measured for each 10 percentile of total length, as defined by frustum sign model method, volumes for each 10 percentile and volumes of all other parts were summed to calculate total femur volume. In order to find calf volume, the distance between tibial point and medial malleolus point was first calculated. After this distance was measured for each 10 percentile of total length, as defined by frustum sign model method, volumes for each 10 percentile and volumes of all other parts were summed to calculate total calf volume.

\subsubsection{Calculation of Foot Volume}

Foot volume was measured using medial malleolus (Ozkan, \& Kin Isler, 2010; Sukul et al., 1993). While the elliptic surface of cross section area $(\mathrm{Si})$ in each part is calculated using, volumes of other consecutive parts between the lines were calculated using Frustum model. When calculating foot volume, hi, i+1 is the distance between consecutive foot parts, and $\mathrm{h}$ value, which is $\mathrm{L} 3 / 2$, is the height between line 1 and foot sole, and it varies depending on the foot. $\mathrm{h}$ value between the third and fourth part is $\mathrm{L} 1 / 2$, which varies depending on the foot. The volume of fifth part is calculated using elliptic parabolic Formula 6, while total foot volume is calculated by summing volumes of all parts (Mayrovitz et al., 2005).

The foot volume was defined by drawing lines between foot sole and medial malleolus point, volumes of different foot parts were calculated as mentioned above, and, finally, volumes of all parts were summed to calculate total foot volume.

\subsubsection{Calculation of Leg Mass}

Femur, calf and feet were measured in order to calculate leg mass. The distance between tibial point and inguinal fold was calculated for the femur. The distance between tibial point and medial malleolus point was calculated for the calf. Finally, the foot was first measured using medial malleolus, and later Havanan model method (Kwon, 1998). "Leg Volume and Mass Calculation Program" developed by Marangoz and Ozbalci (2017) was used for calculation.

\subsection{Statistical Analyses}

SPSS 22.0 package program for Windows was used for descriptive statistics analysis of the study.

\section{Findings}

Leg volume and mass of elite male athletes in some olympic sports are given in Table 1. The findings here suggest that the lowest leg volume and mass are observed in gymnasts (right leg volume: 10739.20 877.74 ; left leg volume:

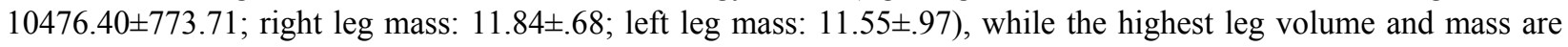
observed in wrestlers. When leg volume and mass values in wrestling, which is a weight sport, are analyzed, the lowest leg volume and mass are observed in 57-61 kg males (right leg volume: $12010.12 \pm 844.59$; left leg volume:

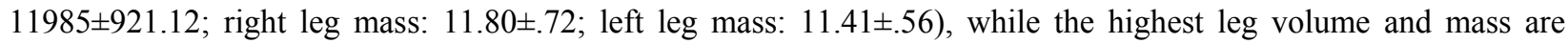
observed in $125 \mathrm{~kg}$ male wrestlers (right leg volume: $21500 \pm 576.40$; left leg volume: $21350 \pm 526.00$; right leg mass: $18.50 \pm .50$; left leg mass: $18.40 \pm .10$ ). 
Table 1. Leg Volume and Mass Scale of Elite Male Athletes in Some Olympic Sports

\begin{tabular}{|c|c|c|c|c|}
\hline & \multicolumn{2}{|c|}{ Volume (ml) } & \multicolumn{2}{|c|}{ Mass (kg) } \\
\hline & Right & Left & Right & Left \\
\hline Football & $10817.80 \pm 844.59$ & $10563.73 \pm 757.10$ & $11.93 \pm .72$ & $11.76 \pm .83$ \\
\hline Volleyball & $10819.20 \pm 844.99$ & $10567.40 \pm 773.78$ & $11.91 \pm .73$ & $11.97 \pm .69$ \\
\hline Basketball & $11006.80 \pm 926.52$ & $10719.06 \pm 919.84$ & $11.88 \pm .68$ & $11.62 \pm .93$ \\
\hline Handball & $10756.66 \pm 861.08$ & $10471.53 \pm 776.69$ & $11.87 \pm .66$ & $11.42 \pm .97$ \\
\hline Gymnastics & $10739.20 \pm 877.74$ & $10476.40 \pm 773.71$ & $11.84 \pm .68$ & $11.55 \pm .97$ \\
\hline Wrestling 57-61 kg & $12010.12 \pm 844.59$ & $11985 \pm 921.12$ & $11.80 \pm .72$ & $11.41 \pm .56$ \\
\hline $65-66 \mathrm{~kg}$ & $13501.05 \pm 956.27$ & $13348.05 \pm 753.27$ & $11.75 \pm .52$ & $11.65 \pm .24$ \\
\hline $70-71 \mathrm{~kg}$ & $14850.02 \pm 847.19$ & $14750.02 \pm 895.20$ & $12.25 \pm .66$ & $12.10 \pm .66$ \\
\hline $74-75 \mathrm{~kg}$ & $14500 \pm 877.74$ & $14320 \pm 573.74$ & $13.94 \pm .68$ & $13.85 \pm .93$ \\
\hline $85-86 \mathrm{~kg}$ & $16500 \pm 926.52$ & $16350 \pm 856.44$ & $14.50 \pm .80$ & $14.40 \pm .40$ \\
\hline $97-98 \mathrm{~kg}$ & $17850 \pm 760.18$ & $17650 \pm 450.10$ & $16.50 \pm .52$ & $16.40 \pm .56$ \\
\hline $125 \mathrm{~kg}$ & $21500 \pm 576.40$ & $21350 \pm 526.00$ & $18.50 \pm .50$ & $18.40 \pm .10$ \\
\hline
\end{tabular}

Table 2. Leg Volume and Mass Scale of Elite Female Athletes in Some Olympic Sports

\begin{tabular}{|c|c|c|c|c|}
\hline & \multicolumn{2}{|c|}{ Volume (ml) } & \multicolumn{2}{|c|}{ Mass (kg) } \\
\hline & Right & Left & Right & Left \\
\hline Football & $11941,53 \pm 650,50$ & $11720,32 \pm 640,10$ & $11,81 \pm, 30$ & $11,78 \pm, 60$ \\
\hline Volleyball & $14514,27 \pm 645,18$ & $14000,76 \pm 630,14$ & $13,16 \pm, 60$ & $13,23 \pm, 56$ \\
\hline Basketball & $13510,20 \pm 520,45$ & $13654,43 \pm 450,40$ & $13,16 \pm, 68$ & $13,13 \pm, 40$ \\
\hline Handball & $13807,16 \pm 620,42$ & $13654,43 \pm 420,31$ & $13,16 \pm, 56$ & $13,13 \pm, 23$ \\
\hline Gymnastics & $13350,20 \pm 650,20$ & $13230,20 \pm 557,52$ & $14,01 \pm, 46$ & $13,50 \pm, 20$ \\
\hline Boxing 48-51 kg & $11159,39 \pm 620,34$ & $10802,38 \pm 510,42$ & $10,814 \pm, 56$ & $11,149 \pm, 56$ \\
\hline $57-60 \mathrm{~kg}$ & $13160,84 \pm 520,40$ & $12737,14 \pm 521,14$ & $13,187 \pm, 50$ & $12,998 \pm, 74$ \\
\hline $71-75 \mathrm{~kg}$ & $17184,06 \pm 425,42$ & $17116,31 \pm 475,23$ & $15,369 \pm, 46$ & $15,198 \pm, 34$ \\
\hline Taekwondo 46-49 kg & $11727,18 \pm 587,43$ & $11227,97 \pm 429,29$ & $11,064 \pm, 50$ & $10,742 \pm, 44$ \\
\hline $49-53 \mathrm{~kg}$ & $12195,29 \pm 523,44$ & $11688,96 \pm 538,39$ & $11,506 \pm, 51$ & $11,134 \pm, 42$ \\
\hline $53-57 \mathrm{~kg}$ & $14844,55 \pm 562,42$ & $14207,49 \pm 548,40$ & $13,162 \pm, 52$ & $13,472 \pm, 52$ \\
\hline $63-67 \mathrm{~kg}$ & $15059,20 \pm 524,40$ & $15487,90 \pm 547,14$ & $13,073 \pm, 49$ & $13,097 \pm, 51$ \\
\hline Tennis & $11131,14 \pm 478,60$ & $11069,15 \pm 489,55$ & $11,35 \pm, 41$ & $11,05 \pm, 20$ \\
\hline
\end{tabular}

Leg volume and mass of elite female athletes in some olympic sports are given in Table 2 . While the lowest leg volume and mass are observed in tennis players (right leg volume: 11131.14 \pm 478.60 ; left leg volume: 11069.15 \pm 489.55 ; right leg mass: $11.35 \pm .41$; left leg mass: $11.05 \pm .20$ ), while the highest leg volume and mass are observed in boxers. In addition, the highest leg volume and mass are observed in 71-75 $\mathrm{kg}$ female boxers (right leg volume: $17184.06 \pm 425.42$; left leg volume: $17116.31 \pm 475.23$; right leg mass: $15.369 \pm .46$; left leg mass: $15.198 \pm .34)$.

\section{Discussion}

The finding in this study were used to create a scale of right and left leg volume and mass of elite male and female athletes in different olympic sports. The scale demonstrates that leg volume and mass of athletes in the lowest weight class were lower and that weight was in direct proportion to leg volume and mass. The scale of elite female athletes 
indicates that volleyball players had the highest leg volume and mass, whereas basketball players had the highest leg volume and mass values among the male athletes.

Temfemo et al. (2009) conducted a study on some anthropometric values and vertical jump performances in adolescent males and females, and reported that leg length and leg mass values of 14, 15 and 16-year-old males were higher compared to females. However, average ages of females and males participating in this study are 21 and 22, respectively. Although no significant differences were observed between leg volume and mass of female and male athletes, it was found out that male wrestlers had higher leg volume and mass compared to other female athletes.

Visser et al. (2002) compared leg mass and composition and lower extremity performance in black males and females aged between 70 and 79, and observed a smaller leg area and more fat infiltration along with a poor lower extremity performance. This study demonstrates that a lower leg volume and mass decreases performance, irrespective of age.

Janssen et al. (2000) analyzed skeletal muscle mass of lower and upper extremity in males and females in different age groups and reported that males had a higher skeletal muscle mass on their lower and upper extremities compared to females. In addition, skeletal muscle mass of the lower extremity decreased in proportion to ageing in both males and females. On the other hand, the present study found out that leg volume and mass of lower extremity in female and male athletes were closer to each other, which may be related to the fact that the participants were elite athletes.

Zorba et al. (2010) indicated in their study on the relationship among leg volume, leg mass, anaerobic performance and leg strength in wrestlers that leg volume and mass played a decisive role in anaerobic performance.

Ozkan et al. (2010) demonstrated that fat-free body mass, leg volume and leg mass played an important role in the determination of anaerobic strength and capacity. Thus, it was underlined that body mass, leg volume and leg mass contributed to anaerobic performance in various sports.

Winter, Brooks and Hamley (2007) carried out a study on the relationship between maximal exercise performance and fat-free leg volume of males and females and reported that maximal exercise performance and leg volume of males were higher compared to females.

\section{Conclusion}

The above-mentioned studies indicate some differences between leg volume and mass of males and females as well as their strength values. The present study, too, revealed difference between leg volume and mass scale of males and females. However, it was observed that the difference was not remarkable and that females in some sports had a higher leg volume and mass compared to males. The reason for this lies in the fact that males and females participating in the present study were elite athletes and their respective olympic sports. In addition, right and left leg volume of male and female athletes in the scale did not yield the same results. Therefore, all athletes are recommended to train their both legs and strengthen their weaker leg in order to display a better performance. For future studies, we recommended to study upper extremity volume and mass and indicate the differences between upper and lower extremity volume and mass both females and male.

\section{References}

Armstrong, N., Welsman, JR., \& Chia, M.Y.H. (2001). Short term power output in relation to growth and maturation. British Journal of Sports Medicine, 35, 118-124. http://dx.doi.org/10.1136/bjsm.35.2.118

Astrand, PO, Rodah, K, Dahl, A.H, Stromme, B.S. (2003). Textbook of work physiology. Australia: Human Kinetics.

Baecchle, T.R., \& Earle, R.W. (2000). Plyometric training. In Potach, D. H. \& Chu, D. A. (Der.), Essential of Strength Training and Conditioning. Canada: Human Kinetics.

De Ste Croix, Armstrong, N., Chia, M. Y. H., Welsman, J. R., Parsons, G., \& Sharpe, P. (2001). Changes in short-term power output in 10-to 12-year-olds. Journal of Sports Sciences, 19(2), 141-148. https://doi.org/10.1080/026404101300036352

Fox, E.L., Bowers, R.W., \& Foss M.L. (2012). Physiological Foundations of Physical Education and Sports (Eds. Mesut Cerit). Ankara.

Janssen, I., Heymsfield, S.B., Wang, Z., \& Ross, R. (2000). Skeletal muscle mass and distribution in 468 men and women aged 18-88 yr. Journal of Applied Physiology, 89(1), 81-88. https://doi.org/10.1152/jappl.2000.89.1.81

Kwon, Y. H. (1998). Modified Hanavan Model. Retrieved 08.9.2016 from 
http://www.kwon3d.com/theory/bspeq/hanavan.html/

Marangoz, I., \& Ozbalci, U. (2017). Leg volume and mass calculation program in sports. The Journal of Academic Social Science, 5(48), 223-231. https://doi.org/10.16992/ASOS.12308

Mayrovitz, H. N., Sims, N., Litwio, B., \& Pfister, S. (2005). Foot Volume Estimates Based on a Georietric Algorithm in Comparison to Water Displacement. Lymphology, 38, 20-2.

Ozkan, A., \& Kin Isler, A. (2010). Relationships of leg volume, leg mass, anaerobic performance and isokinetic strength in american football players. Spormetre, 8(1), 35-41.

Ozkan, A., Koklu, Y., Akin, M., \& Ersoz, G. (2010). The role of body composition, leg volume and leg mass in determining anaerobic performance in climbers. E-Journal of New World Sciences Academy, 5(1), 59-70.

Shumway-Cook A., \& Woollacott M. H. (2007). Motor control: translating research into clinical practice. Lippincott Williams \& Wilkins. Wolters Kluwer business

Staron, R.S., Hagerman, F.C., Hikida, R.S., Murray, T.F., Hostler, D.P., \& Crill, M.T. et al. (2000). Fiber type composition of the vastus lateralis muscle of young men and women. The Journal of Histochemistry and Cytochemistry, 48(5), 623-629. https://doi.org/10.1177/002215540004800506

Sukul, D.K., Den Hoed, P.T., Johannes, E.J., Van Dolder, R., \& Benda, E. (1993). Direct and indirect methods for the quantification of leg volume: comparison between water displacement volumetry, the disk model method and the frustum sign model method, using the correlation coefficient and the limits of agreement. Journal of biomedical engineering, 15(6), 477-480. https://doi.org/10.1016/0141-5425(93)90062-4

Visser, M., Kritchevsky, S.B., Goodpaster, B.H., Newman, AB., Nevitt, M., Stamm E., \& Harris, T.B. (2002). Leg muscle mass and composition in relation to lower extremity performance in men and women aged 70 to 79: the health, aging and body composition study. Journal of the American Geriatrics Society, 50(5), 897-904. https://doi.org/10.1046/j.1532-5415.2002.50217.x

Winter, E.M., Brookes, F.B.C., \& Hamley, E.J. (2007). Maximal exercise performance and lean leg volume in men and women. Journal of Sports Sciences, 9(1), 3-13. https://doi.org/10.1080/02640419108729850

Zorba, E., Ozkan, A., Akyuz, M., Harmanci, H., Tas, M., \& Senel, O. (2010). The relationship of leg volume and leg mass with anaerobic performance and knee strength in wrestlers. Journal of Human Sciences, 7(1), 84-96. 